\title{
VIABILIDADE in vitro DE GRÃOS DE PÓLEN DE BANANEIRA SOB DIFERENTES CONCENTRAÇÕES DE ÁCIDO BÓRICO E SACAROSE
}

\author{
In vitro viability of banana pollen grain under different concentrations of boric acid and sucrose
}

\author{
Ronaldo Viana dos Reis ${ }^{1}$, Lucymeire de Souza Morais-Lino ${ }^{2}$, Sebastião de Oliveira e Silva ${ }^{3}$, \\ Edson Perito Amorim ${ }^{3}$, Carlos Alberto da Silva Ledo ${ }^{3}$, Alexandre Pio Viana ${ }^{4}$
}

\begin{abstract}
RESUMO
Neste trabalho, objetivou-se avaliar a germinação do grão de pólen e o comprimento do tubo polínico das bananeiras diplóides M53, 8987-01 e 9197-03, Calcutá, Lidi e 86B79-12. O delineamento utilizado foi inteiramente casualizado com cinco doses de sacarose $(0,5,10,15,20 \%)$ e seis concentrações de ácido bórico $\left(0,100,200,300,400\right.$ e $\left.500 \mathrm{Mg} \mathrm{L}^{-1}\right)$ com quatro repetições. Foram utilizados grãos de pólen retirados da inflorescência masculina dos diplóides Musa acuminata (AA). O pólen foi distribuído em placas de Petri, contendo o seguinte meio de cultura: $1,27 \mathrm{mM}$ de $\mathrm{Ca}\left(\mathrm{NO}_{3}\right)_{2} \cdot 2 \mathrm{H}_{2} \mathrm{O}, 0,87 \mathrm{mM} \mathrm{de} \mathrm{MgSO}_{4} \cdot 7 \mathrm{H}_{2} \mathrm{O}$, $0,99 \mathrm{mM}$ de $\mathrm{KNO}_{3}, 0,7 \%$ de ágar com pH ajustado para 7,0, variando as concentrações de sacarose e de ácido bórico. As avaliações foram realizadas 24 horas após a distribuição do pólen no meio de cultura. O meio de cultura padrão para germinação de grãos de pólen suplementado com $15 \%$ de sacarose proporcionou uma maior percentagem de germinação para os diplóides de bananeira avaliados. A concentração de ácido bórico adicionado ao meio de cultura para a germinação de grãos de pólen de bananeira diplóide é dependente do genótipo.
\end{abstract}

Termos para indexação: Musa acuminata, diplóides, germinação, tubo polínico.

\section{ABSTRACT}

The objective of this work was to evaluate the germination of pollen grain and pollen tube length of banana diploids (M53, 8987-01 e 9197-03, Calcutta, Lidi and 86B79-12). Five concentrations of sucrose (0, 5, 10, 15 and 20\%) and six concentrations of boric acid $\left(0,100,200,300,400\right.$ and $\left.500 \mathrm{mg} \mathrm{L}^{-1}\right)$ were used, in a completely randomized experimental design, with four replicates. The pollen was distributed in Petri dishes containing the following culture medium: $1.27 \mathrm{mM}$ $\mathrm{Ca}(\mathrm{NO} 3)_{2} .2 \mathrm{H}_{2} \mathrm{O}, 0.87 \mathrm{mM} \mathrm{MgSO}_{4} .7 \mathrm{H}_{2} \mathrm{O}, 0.99 \mathrm{mM} \mathrm{KNO}_{3}$, and $0.7 \%$ agar; $\mathrm{pH}$ adjusted to 7.0 , varying the sucrose and boric acid concentrations. The evaluations were performed 24 hours after the distribution of the pollen in the culture medium. The standard culture medium for germination of pollen grains with $15 \%$ sucrose provided the highest germination percentage for the banana diploids. The concentration of boric acid added to the culture medium for pollen grain germination of diploid banana is dependent on the genotype.

Index terms: Musa acuminata, diploids, germination, pollen tube.

(Recebido em 13 de janeiro de 2009 e aprovado em 6 de julho de 2010)

\section{INTRODUÇÃO}

A transferência de genes de interesse em espécies cultivadas, muitas vezes, é limitada em virtude das barreiras existentes durante o processo de polinização, fertilização e embriogênese (Zenkteler, 1990).

A fertilidade do grão de pólen é condição preliminar indispensável ao melhoramento genético clássico, uma vez que dados sobre a viabilidade e o desenvolvimento de grãos de pólen são fundamentais para os estudos da biologia reprodutiva e para o desenvolvimento de programas de melhoramento genético, pois permitem obter maiores sucessos nos cruzamentos realizados (Flanklin et al., 1995).
A germinação in vitro é o método mais utilizado em testes de viabilidade de pólen (Marcellán \& Camadro, 1996). Entretanto, o desenvolvimento desse método é influenciado por diferentes fatores, entre eles: os constituintes do meio de cultura, a temperatura e o tempo de incubação. A cultura de tecido vem sendo utilizada no intuito de melhorar os meios de culturas in vitro e suas varias funções (Camolesi, et al., 2010). A viabilidade do pólen também é influenciada pelo estádio de desenvolvimento da flor, quando da coleta do pólen, e pelas condições de armazenamento (Stanley \& Linskens, 1974).

O meio básico usado nesses testes é constituído de açúcar e de ácido bórico, podendo variar ainda a

${ }^{1}$ Universidade Federal de Viçosa/UFV - Avenida P. H. Holfs - s/n - 36570-000 - Viçosa, MG - ronaldo.viana@ufv.br

2Universidade Estadual de Feira de Santana/UEFS - Feira de Santana, BA

${ }^{3}$ Empresa Brasileira de Pesquisa Agropecuária/Embrapa - Mandioca e Fruticultura - Cruz das Almas, BA

${ }^{4}$ Universidade Estadual do Norte Fluminense Darcy Ribeiro/UENF - Campos dos Goytacazes, RJ 
combinação de outros nutrientes (Galletta, 1983, Miranda \& Clement, 1990). O açúcar promove o equilíbrio osmótico entre o pólen e o meio de germinação, e fornece energia para o desenvolvimento do tubo polínico (Stanley \& Linskens, 1974). O boro estimula o crescimento do tubo polínico e diminui a probabilidade destes se romperem (Franzon \& Raseira, 2006).

A adição de ácido bórico, de um modo geral, aumenta a eficiência da sacarose na germinação do pólen e no crescimento do tubo polínico (Almeida et al., 1987). O boro juntamente com o cálcio são elementos essenciais para o início do prolongamento da intina e formação do tubo polínico in vitro (Brewbaker \& Kwack, 1963).

Pio et al. (2004), em algumas cultivares de Citrus, observaram que o boro na concentração de $200 \mathrm{mg} \mathrm{L}^{-1}$ estimula a germinação de grãos de pólen das cultivares Pêra e Natal. Silva et al. (1999) concluiram que $200 \mathrm{mg} \mathrm{L}^{-1} \mathrm{de}$ ácido bórico forneceu as melhores condições para germinação dos grãos de pólen do maracujazeiro amarelo. Almeida et al. (1987), trabalhando com grãos de pólen de algodão mostraram que $300 \mathrm{mg} \mathrm{L}^{-1}$ de ácido bórico obteve maior porcentagem de germinação.

A germinação de grão de pólen de citros, na ausência de boro resulta em maior rompimento das membranas do tubo polínico, liberando o conteúdo citoplasmático para o meio exterior (Pio et al., 2004).

A germinação in vitro de grãos de pólen de macieira não teve efeito positivo na presença de ácido bórico (Dantas et al., 2005). A adição de boro ao meio de cultura mostra respostas variáveis, conforme a espécie e seu mecanismo de ação, consiste em interagir com o açúcar e formar um complexo ionizável açúcar-borato, o qual reage mais rapidamente com as membranas celulares (Pfahler, 1967; Askin et al., 1990).

Objetivou-se, neste trabalho, avaliar a germinação de grãos de pólen e o comprimento do tubo polínico de diplóides de bananeira em meio de cultura padrão com diferentes concentrações de sacarose e ácido bórico.

\section{MATERIAL E MÉTODOS}

O trabalho foi conduzido no laboratório de Biotecnologia Vegetal da Embrapa Mandioca e Fruticultura Tropical. Como material vegetal foram utilizados grãos de pólen de bananeira de seis diplóides gerados pelo programa de melhoramento da Embrapa Mandioca e Fruticultura tropical, resistentes à Sigatoka Negra.

Coletaram-se brácteas contendo flores masculinas de cada genótipo às 8 horas da manhã, que foram encaminhadas para o laboratório para serem trabalhas em câmara de fluxo laminar.
Os grãos de pólen foram retirados das anteras, com auxílio de um bisturi e misturados em placa de Petri, em seguida, com um pincel foram distribuídos na superfície do meio de cultura, de modo a promover uma distribuição mais homogênea do material. Os grãos de pólen dos diplóides M53, 9179-03 e 8987-01 foram distribuídos em placas de Petri de $9 \mathrm{~cm}$ de diâmetro, contendo $30 \mathrm{~mL}$ de meio de cultura $300 \mathrm{mg} \mathrm{L}^{-1} \mathrm{de} \mathrm{Ca}\left(\mathrm{NO}_{3}\right)_{2} .2 \mathrm{H}_{2} \mathrm{O}, 200 \mathrm{mg} \mathrm{L}^{-1}$ de $\mathrm{MgSO}_{4} \cdot 7 \mathrm{H}_{2} \mathrm{O}, 100 \mathrm{mg} \mathrm{L}{ }^{-1}$ de $\mathrm{KNO}_{3}, 1,62 \mathrm{mM}$ de H3BO3, 0,7\% de Agar com pH ajustado para 7,0, variando-se a concentração de sacarose $(0,5,10,15,20 \%)$. Os grãos de pólen dos diplóides Calcutá, Lidi, 86B79 12, 8987-01 e 9179-03 foram distribuídos em placas de Petri de $9 \mathrm{~cm}$ de diâmetro, contendo $30 \mathrm{~mL}$ de meio de cultura $\left[300 \mathrm{mg} \mathrm{L}^{-1} \mathrm{de} \mathrm{Ca}\left(\mathrm{NO}_{3}\right)_{2} .2 \mathrm{H}_{2} \mathrm{O}, 200 \mathrm{mg} \mathrm{L}^{-1} \mathrm{de}\right.$ $\mathrm{MgSO}_{4} .7 \mathrm{H}_{2} \mathrm{O}, 100 \mathrm{mg} \mathrm{L}^{-1}$ de $\mathrm{KNO}_{3}, 15 \%$ de sacarose $0,7 \%$ de agar com pH ajustado para 7,0 variando seis concentrações de ácido bórico $(0,100,200,300,400$ e $500 \mathrm{mg} \mathrm{L}^{-1}$ ). Os meios de cultura foram autoclavados à $120^{\circ} \mathrm{C}$ por $15 \mathrm{~min}$.

As placas foram mantidas em condições controladas de temperatura $\left(27 \pm 1^{\circ} \mathrm{C}\right)$, no escuro, antes de se realizar a contagem dos grãos de pólen germinados e a medição do comprimento do tubo polínico.

O delineamento utilizado foi o inteiramente casualizado em arranjo fatorial, com 15 tratamentos, com três diplóides (M53, 8987-01 e 9179-03), cinco doses de sacarose $(0 ; 5 ; 10 ; 15$ e $20 \%)$ e quatro repetições.

$\mathrm{O}$ segundo experimento seguiu o mesmo delineamento, com 30 tratamentos, foi realizado com cinco diplóides de bananeira (Lidi, 8987-01, 9179-03, Calcuta e 86B79-12), seis concentrações de ácido bórico $(0,0 ; 100$; 200; 300; 400 e $500 \mathrm{mg} \mathrm{L}^{-1}$ ) e quatro repetições.

As avaliações foram realizadas 24 horas após a distribuição do pólen no meio de cultura. Foram considerados germinados os grãos de pólen onde o comprimento do tubo polínico atingisse ou ultrapassasse o seu diâmetro. Com auxilio de um estereomicroscópio procedeu-se à contagem dos grãos de pólen germinados e o comprimento do tubo polínico foi medido, utilizando uma ocular micrométrica e os dados foram transformados para milímetros. Foram contabilizados grãos de pólen germinados e não-geminados, e para o comprimento foram selecionados aleatoriamente dez tubos polínicos e mensurados em cada repetição.

Os dados foram submetidos a analise de variância e os graus de liberdades entre os fatores, assim com de suas interações, foram desdobrados vias teste de comparações de médias e análise de regressão polinomial, com nível de significância a 5\% de probabilidade. 


\section{RESULTADOS E DISCUSSÃO}

Houve diferenças significativas nos valores de germinação dos grãos de pólen, tanto dentro das concentrações de sacarose quanto entre diplóides.

Observaram-se uma grande quantidade de grãos de pólen estourados nos genótipos em meio sem sacarose (Figura 1). A germinação desses genótipos foi muito baixa, variando de 0,25\% do diplóide M53 a 6,62\% para o diplóide 8987-01 (Tabela 1). Segundo Stanley \& Linskens (1974), a sacarose promove o equilíbrio osmótico entre o pólen e o meio de germinação, e fornece energia para o desenvolvimento do tubo polínico.

Em todas as concentrações de sacarose, o diplóide 9179-03 apresentou o mais baixo percentual de germinação (Figura 2), seus valores de germinação variou de $0,25 \%$ na concentração de $0 \%$ de sacarose a $6,7 \%$ na concentração de $15 \%$ de sacarose demonstrando a baixa eficiência de germinação dos grãos de pólen desse genótipo (Tabela 1).

O diplóide 8987-01 apresentou níveis de germinação, variando de $6,62 \%$ na concentração $0 \%$ de sacarose a $62,82 \%$ na concentração de $15 \%$ de sacarose (Tabela 1). O que demonstra uma diferença siguinificativa entre esses dois genótipos em relação a sua germinação e esses dados são importantes e vêm sendo usados para orientar novos cruzamentos dentro do programa de melhoramento de diplóides da Embrapa Mandioca e Fruticultura Tropical.

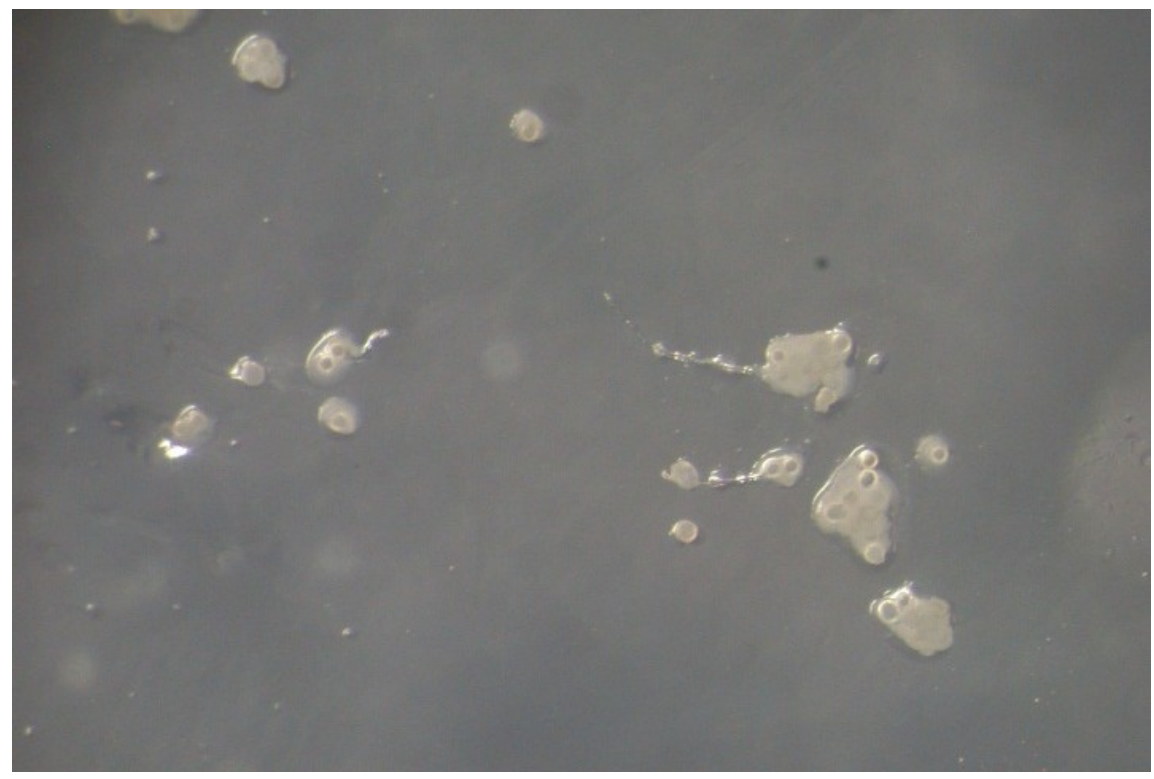

Figura 1 - Grãos de pólen do diplóide 9179-03 em meio de cultura padrão sem sacarose.

Tabela 1 - Porcentagem de germinação de grãos de pólen dos diplóides de bananeira 9197-03, M-53 e 8987-01 em meio de cultura padrão com diferentes doses de sacarose (0, 5, 10, 15 e 20\%), Cruz das Almas - BA, Embrapa Mandioca e Fruticultura Tropical, 2008.

\begin{tabular}{|c|c|c|c|}
\hline Doses de & Diplóide & Diplóide & Diplóide \\
\hline sacarose (\%) & 9179-03 (\%) & M-53 & 8987-01 (\%) \\
\hline 5 & $2,38 \mathrm{cB}$ & $16,47 \mathrm{bC}$ & $43,07 \mathrm{aB}$ \\
\hline 10 & $4,93 \mathrm{bA}$ & $33,45 \mathrm{aB}$ & $34,89 \mathrm{aB}$ \\
\hline 15 & $6,72 \mathrm{bA}$ & $69,33 \mathrm{aA}$ & $62,82 \mathrm{aA}$ \\
\hline 20 & $1,66 \mathrm{bB}$ & $55,31 \mathrm{aA}$ & $57,02 \mathrm{aA}$ \\
\hline 0 & $0,25 \mathrm{cC}$ & $1,17 \mathrm{bD}$ & $6,62 \mathrm{aC}$ \\
\hline
\end{tabular}

Médias seguidas pelas mesmas letras minúscula na linha e maiúscula na coluna não diferem entre si pelo teste Tukey a 5\% de probabilidade do erro. 
Dentre os diplóides avaliados, o M-53 teve o maior índice de germinação (Figura 3), apresentando um alto nível de germinação $69 \%$ na concentração de $15 \%$ de sacarose (Tabela 1). Dentre outras características favoráveis desse diplóide como resistência a doenças, essa alta germinação é uma das mais importantes, pois, este diplóide é muito usado em programas de melhoramento dessa cultura. A viabilidade de seus grãos de pólen é fundamental para a transmissão de suas características favoráveis.

Dentre as concentrações de sacarose testadas, a melhor resposta em germinação foi obtida na concentração de $15 \%$ sacarose, uma vez que, os diplóides M53 e 8987-01 tiveram os maiores percentuais de germinação, 69,33\% e 62,82\%, respectivamente, já, o diplóide 9179-03 apresentou baixos percentuais de germinação 6,72\% (Tabela 1).

A análise de variância dos dados da germinação de grãos de pólen e comprimento do tubo polínico de cinco diplóides de bananeira e seis concentrações de ácido bórico revelou diferenças significativas $(\mathrm{P}<0,05)$ para todos os fatores.

As médias de germinação de grãos de pólen dos diplóides de bananeira submetidos a diferentes concentrações de ácido bórico são apresentadas na Tabela 2. Para essa variável, observa-se que na ausência de ácido bórico, não houve diferenças entre os diplóides estudados, com taxas abaixo de $4 \%$. As maiores porcentagens de germinação foram obtidas para o diplóide 8987-01, nas concentrações de 200 e $400 \mathrm{mg} \mathrm{L}^{-1}$ e para o diplóide 9179-03 na concentração de $300 \mathrm{mg} \mathrm{L}^{-1}$, com valores de $87,71,79,48$ e $82,59 \%$, respectivamente. Valores semelhantes foram obtidos por Silva et al. (1999), que concluíram que $200 \mathrm{mg} \mathrm{L}^{-1}$ de ácido bórico forneceu as melhores condições para germinação dos grãos de pólen do maracujazeiro amarelo.

Com relação ao comprimento do tubo polínico, os valores variaram, também, conforme o diplóide estudado e as concentrações utilizadas (Tabela 2). Para a concentração de $300 \mathrm{mg} \mathrm{L}^{-1}$, o diplóide Lidi foi estatisticamente superior às demais, com 20,06 mm. Para a concentração de $500 \mathrm{mg} \mathrm{L}^{-1}$, os diplóides Lidi e 86B79-12, não diferiram estatisticamente entre si, com valores de 19,50 e 21,38 mm, respectivamente. Não houve diferenças significativas entre os diplóides para as concentrações de 0 e $400 \mathrm{mg} \mathrm{L}^{-1}$. Dantas et al. (2005), mostraram que o ácido bórico não teve efeito positivo para essa característica em experimento com maçã, enquanto Milutinovic et al. (1996), obtiveram resultados positivos utilizando ácido bórico em variedades distintas de macieiras, 64,2 e $88,3 \%$ de germinação para as cultivares Jonathan e Golden Delicious, respectivamente.

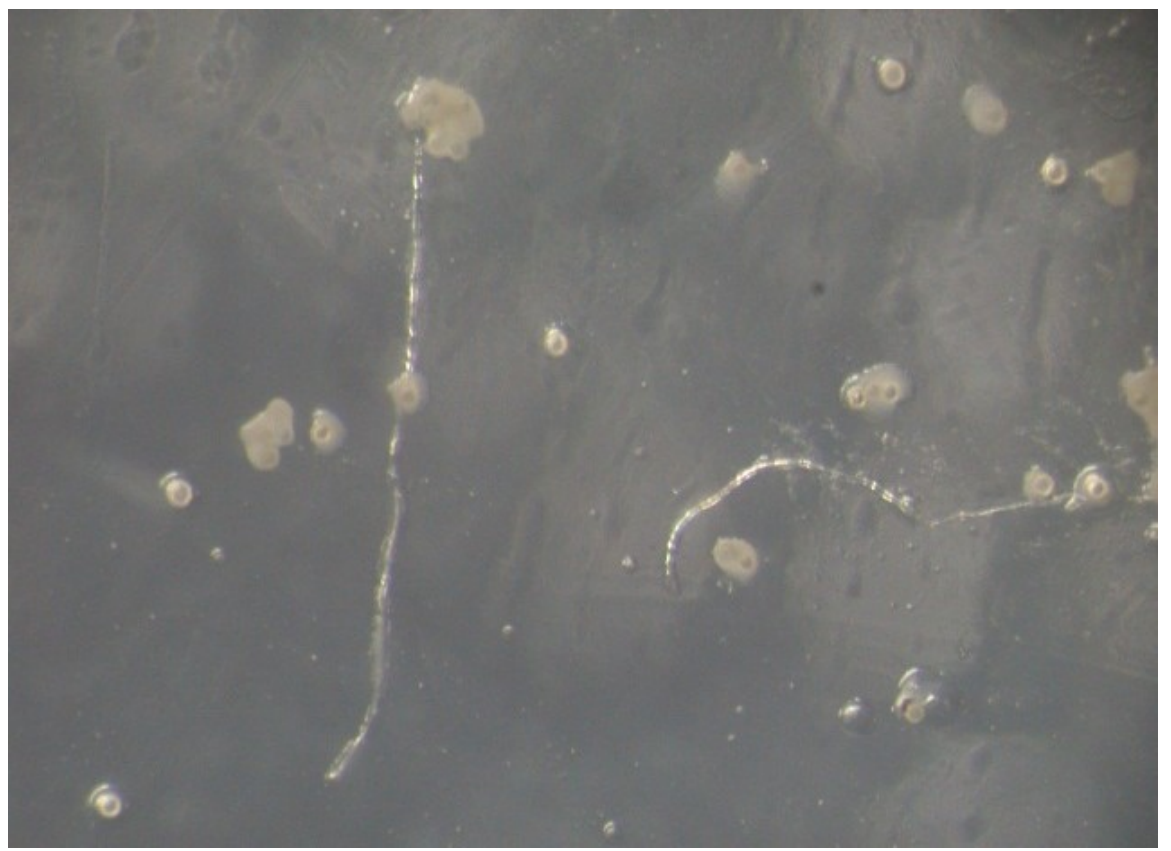

Figura 2 - Grãos de pólen do diplóide 9179-03 em meio de cultura padrão com 15\% de sacarose. 


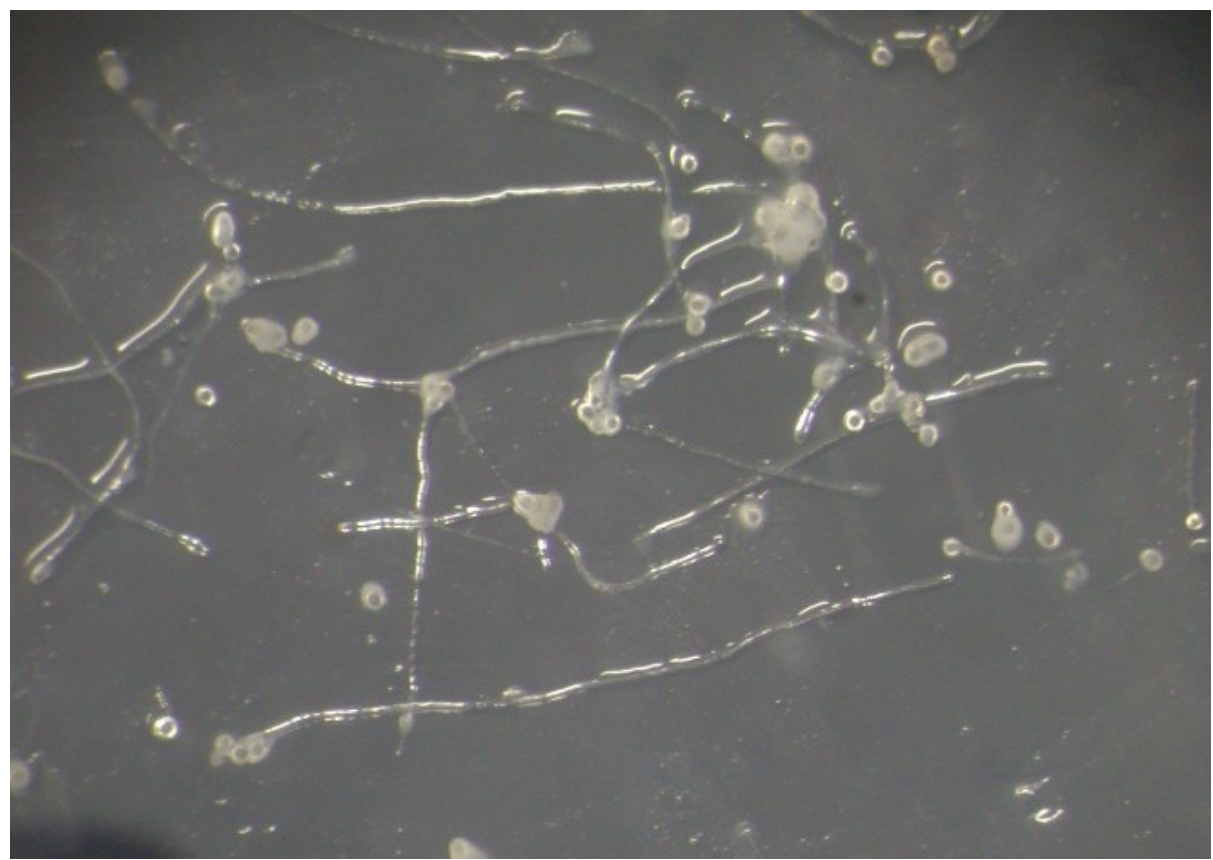

Figura 3 - Grãos de pólen do diplóide M53 em meio de cultura padrão com 15\% de sacarose.

Tabela 2 - Valores médios de germinação de grãos de pólen e comprimento de tubo polínico para os diplóides de bananeira submetidas a diferentes concentrações de ácido bórico $\left(\mathrm{mg} \mathrm{L}^{-1}\right)$ Cruz das Almas - BA, Embrapa Mandioca e Fruticultura Tropical, 2008.

\begin{tabular}{ccccccc}
\hline \multirow{2}{*}{ Variedades } & \multicolumn{7}{c}{ Concentrações de ácido bórico } \\
\cline { 2 - 7 } & 0 & 100 & \multicolumn{7}{c}{ Grãos de pólen germinados $(\%)$} \\
\hline Calcutá & $0,1761 \mathrm{a}$ & $75,8256 \mathrm{a}$ & $25,9337 \mathrm{c}$ & $36,4547 \mathrm{c}$ & $66,1168 \mathrm{~b}$ & $62,3547 \mathrm{a}$ \\
Lidi & $1,7951 \mathrm{a}$ & $79,0147 \mathrm{a}$ & $60,4389 \mathrm{~b}$ & $65,7016 \mathrm{~b}$ & $55,3873 \mathrm{c}$ & $59,1242 \mathrm{a}$ \\
$9179-03$ & $1,6265 \mathrm{a}$ & $29,5985 \mathrm{~b}$ & $32,3935 \mathrm{c}$ & $82,5949 \mathrm{a}$ & $36,8211 \mathrm{~d}$ & $40,2662 \mathrm{~b}$ \\
$8987-01$ & $1,8243 \mathrm{a}$ & $74,4967 \mathrm{a}$ & $79,4844 \mathrm{a}$ & $41,3237 \mathrm{c}$ & $87,7106 \mathrm{a}$ & $3,1344 \mathrm{c}$ \\
$86 \mathrm{~B} 79-12$ & $3,1344 \mathrm{a}$ & $31,7061 \mathrm{~b}$ & $53,1434 \mathrm{~b}$ & $68,4778 \mathrm{~b}$ & $49,8704 \mathrm{~d}$ & $68,0381 \mathrm{a}$ \\
\hline & & \multicolumn{7}{c}{ Comprimento do tubo polínico (mm) } \\
\hline Calcuta & $8,0000 \mathrm{a}$ & $16,2500 \mathrm{a}$ & $11,5625 \mathrm{c}$ & $12,8750 \mathrm{~b}$ & $14,5625 \mathrm{a}$ & $13,9375 \mathrm{~b}$ \\
Lidi & $3,2500 \mathrm{a}$ & $10,5000 \mathrm{~b}$ & $18,2500 \mathrm{a}$ & $20,0625 \mathrm{a}$ & $16,3750 \mathrm{a}$ & $19,5000 \mathrm{a}$ \\
$9179-03$ & $3,2500 \mathrm{a}$ & $17,5000 \mathrm{a}$ & $15,1875 \mathrm{~b}$ & $15,3125 \mathrm{~b}$ & $15,3125 \mathrm{a}$ & $14,4375 \mathrm{~b}$ \\
$8987-01$ & $4,0833 \mathrm{a}$ & $20,1875 \mathrm{a}$ & $18,0000 \mathrm{a}$ & $16,6875 \mathrm{~b}$ & $17,5625 \mathrm{a}$ & $6,0000 \mathrm{c}$ \\
$86 \mathrm{~B} 79-12$ & $6,0000 \mathrm{a}$ & $17,7500 \mathrm{a}$ & $21,1250 \mathrm{a}$ & $16,8125 \mathrm{~b}$ & $12,9375 \mathrm{a}$ & $21,3750 \mathrm{a}$ \\
\hline
\end{tabular}

Médias seguidas pela mesma letra nas colunas pertencem ao mesmo grupo pelo teste de Tukey $5 \%$ de probabilidade do erro.

Na Tabela 3, são apresentados às equações polinomiais ajustadas, com seus respectivos valores dos coeficientes de determinação e pontos de máximo, para os diferentes diplóides de bananeira em função das concentrações de ácido bórico $\left(\mathrm{mg} \mathrm{L}^{-1}\right)$. Para a variável porcentagem de germinação dos grãos de pólen para o 
Tabela 3 - Equações polinomiais, coeficientes de determinação $\left(\mathrm{R}^{2}\right)$ e pontos de máximo de germinação de grãos de pólen e comprimento do tubo polínico para diplóides de bananeira submetidos a diferentes concentrações de ácido bórico (mg L $\left.{ }^{-1}\right)$. Cruz das Almas - BA, Embrapa Mandioca e Fruticultura Tropical, 2008.

\begin{tabular}{|c|c|c|c|}
\hline Variedades & Equação & $\mathrm{R}^{2}$ & Ponto de máximo \\
\hline & \multicolumn{3}{|c|}{ Grãos de pollen germinados $(\%)$} \\
\hline Calcutá & $-(1)$ & - & - \\
\hline Lidi & $\hat{y}^{* *}=-0,0006 x^{2}+0,3617 x+17,887$ & 0,5705 & 301,4167 Máx. \\
\hline 9179-03 & $\hat{y} * *=-0,0006 x^{2}+0,3587 x-0,5803$ & 0,6437 & 298,9167 Máx. \\
\hline $8987-01$ & $\hat{y}^{* *}=-0,0011 \mathrm{x}^{2}+0,5564 \mathrm{x}+10,479$ & 0,6148 & 252,9091 Máx. \\
\hline \multirow[t]{2}{*}{$86 \mathrm{~B} 79-12$} & $\hat{y}^{* *}=-0,0004 x^{2}+0,3021 x+4,93$ & 0,8900 & 377,625 Máx. \\
\hline & \multicolumn{3}{|c|}{ Comprimento do tubo polínico (mm) } \\
\hline Calcutá & - & - & - \\
\hline Lidi & $\hat{y} * *=-0,0001 x^{2}+0,088 x+3,5134$ & 0,9136 & 440,0000 Máx. \\
\hline $9179-03$ & $\hat{y} * *=-0,0001 x^{2}+0,0734 x+6,0134$ & 0,6657 & 367,0000 Máx. \\
\hline $8987-01$ & $\hat{y} * *=-0,0002 x^{2}+0,1127 x+6,2202$ & 0,8013 & 281,7500 Máx. \\
\hline 86B79-12 & - & - & - \\
\hline
\end{tabular}

${ }^{(1)}$ sem ajuste de equações significativas com significado biológico.

diplóide Calcutá, não foi possível o ajuste de equação significativa e com significado biológico. As concentrações que propiciaram a máxima germinação para os diplóides 8987-01 e 86B79-12 variaram de 252, 91 a 377 , $63 \mathrm{mg} \mathrm{L}^{-1}$, respectivamente. A variável comprimento do tubo polínico para os diplóides Calcutá e 86B79-12, não foi possível o ajuste de equação significativa e com significado biológico. Os valores de ácido bórico para os diplóides 8987-01 e Lidi que propiciaram o maior comprimento do tubo polínico variaram de 281,75 a $440,00 \mathrm{mg} \mathrm{L}^{-1}$, respectivamente.

Os resultados obtidos neste experimento são semelhantes ao encontrados em outras espécies (Almeida et al., 1987; Silva et al., 1999; Pio et al., 2004).

\section{CONCLUSÕES}

O meio de cultura padrão para a germinação de grãos de pólen suplementado com $15 \%$ de sacarose, proporciona uma maior percentagem de germinação para os diplóides de bananeira avaliados.

A concentração de ácido bórico adicionado ao meio de cultura para a germinação de grãos de pólen de bananeira diplóide é dependente do genótipo.

\section{REFERÊNCIAS BIBLIOGRÁFICAS}

ALMEIDA, F.C.G.; SILVA, J.F. da; ALVES, J.F.; SI LVA, F.P. da; ALMEIDA, F.A.G. Estudo da germinação do pólen do algodão, Gossypium hirsutum L. in vitro: II., efeitos do ácido bórico e do sulfato de manganês.

Ciência Agronômica, Fortaleza, v.18, n.1, p.117-123, 1987.

ASKIN,A.; HEPAKSOY, S.; OZCAGIRAN, R. Investigations on the effects of gibberellic acid and boric acid on the germination of some sweet cherry pollens. Ege Universite Ziraat Fakultesi Dergise, Dergise, v.27, n.3, p.105-116, 1990.

BREWBAKER, J.L.; KWACK, B.H. The essential role of calcium ion in pollen germination and pollen tube growth. American Journal of Botany, Lancaster, v.50, n.9, p.859-865, 1963.

CAMOLESI, M.R.; MARTINS, A.N.; SOUZA, L.D. de; SACONI, C.G. Enraizamento in vitro de mudas micropropagadas de bananeira (Musa sp.) em diferentes meios de cultivo. Ciência e

Agrotecnologia, Lavras, v.34, n.6, p.1446-1451, nov./dez., 2010.

DANTAS, A.C. de M.; PEIXOTO, M.L.; NODARI, R.O.; GUERRA, M.P. Viabilidade do pólen e desenvolvimento do tubo polínico em macieira (Malus spp.). Revista

Brasileira de Fruticultura, Jaboticabal, v.27, n.3, p.356$359,2005$. 
FLANKLIN, F.H.C.; LAWRENCE, M.J.; FLANKLINTONG, V.E. Cell and molecular biology of selfincompatibility in flowering plants. International Review of Cytology, Cambridge, v.158, p.1-62, 1995.

FRANZON, R.C.; RASEIRA, M.C.B. Germinação in vitro e armazenamento do pólen de Eugenia involucrata DC (MYRTACEAE). Revista Brasileira de Fruticultura, Jaboticabal, v.28, n.1, p.18-20, 2006.

GALLETA, G.J. Pollen and seed management. In: MOORE, J.N.; JANICK, J. (Eds.). Methods in fruits breeding. Indiana: Purdue University, 1983. p.23-47.

MARCELLÁN, O.N.; CAMADRO, E.L. The viability of asparagus pollen after storage at low temperatures.

Scientia Horticulturae, Amsterdam, v.67, p.101-104, 1996.

MILUTINOVIC, M.; MOMIROVIC, G.S.; NIKOLIC, D. Functionality of poll and fruit set in apples. Acta Horticulturae, Wageningen, v.423, p.167-169, 1996.

MIRANDA, P.A.; CLEMENT, C.R. Germination and storage of pejibaye (Bactris gasipaes) Palmae pollen. Revista de Biologia Tropical, San Jose, v.38, n.1, p.29-33, 1990.
PFAHLER, P.L. In vitro germination and pollen tube growth of maize (Zea mays L.) pollen: calcium and boron effects. Canadian Journal of Botany, Toronto, v.45, p.839-845, 1967.

PIO, L.A.S.; SANTOS, F.C.; RUFINI, J.C.M.; RAMOS, J.D.; ARAÚJO, A.G. Germinação in vitro de pólen de citros sob diferentes concentrações de cálcio e boro. Revista Brasileira de Agrociência, Goiânia, v.10, n.3, p.293-296, 2004.

SILVA, M.M.; BRUCKNER, C.H.; PICANÇO, M.; CRUZ, C.D. Fatores que afetam a germinação do grão de pólen do maracujá: meios de cultura e tipos de agrotóxicos. Pesquisa Agropecuária Brasileira, Brasília, v.34, n.3, p.347-352, mar. 1999.

STANLEY, R.G.; LINSKENS, H.F. Pollen: biology, biochemistry and management. New York: SpringerVerlag, 1974. 172p.

ZENKTELER, M. In vitro fertilization amd wide hybridization higher plants. Critical Review in Plant Sciences, London, v.9, n.3, p.267-279, 1990. 